European Archives of Psychiatry \& Clinical Neuroscience, 247, 146-153.

RAMSAY, M. \& SPILLER, J. (1997) Drug Misuse Declared in 1996. Latest Results from the British Crime Survey. London: Home Office.

SHANER, A., KHALSA, M. E., ROBERTS, L., et al (1993) Unrecognised cocaine abuse amongst schizophrenic patients. American Journal of Psychiatry, 150 $758-762$.

WEAVER, T., RUTTER, D., MADDEN, P., et al (2001) Results of a screening survey for co-morbid substance misuse amongst patients in treatment for psychiatric disorders: prevalence and service needs in an inner London
Borough. Social Psychiatry and Psychiatric Epidemiology, 36 399-406.

(1992)

The ICD-10 Classification of Mental and Behavioural Disorders. Geneva: WHO

Ann Ley Research Psychologist, Psychology Department, Torbay Hospita ${ }^{*}$ David Jeffery Consultant Clinical Psychologist, Kitson Hall, Torbay Hospital, TorquayTQ2 7AA， José Ruiz Staff Grade in Psychiatry, Waverley House, Torquay, Stuart McLaren Consultant Psychiatrist, Specialist in Addiction, Shrublands House, Torquay, Chris Gillespie Consultant Psychiatrist, The Laurels, Newton Abbot Hospital

\title{
MIDAS: a new service for the mentally ill with comorbid drug and alcohol misuse
}

\section{AIMS AND METHOD}

To describe the work and patient characteristics of one of the first combined mental illness and drug and alcohol services (MIDAS) in the UK. We examined MIDAS as an assertive community service, for individuals receiving long-term community care. We selected the case files of the first 80 patients accepted over a 10 month period and examined variables including demographic details, diagnosis, associated substance use and length of engagement with the service.

\begin{abstract}
RESULTS
Our findings show that there was no relationship between responders to the service and basic demographic data. Patients with bipolar affective disorder and personality disorders were more likely to use the service than patients with unipolar disorder or schizophrenia. Despite the use of an assertive service, there was difficulty engaging patients with schizophrenia and comorbid drug use. These same patients also had a high level of criminal convictions as well as a trend towards using alcohol and cannabis
\end{abstract}

as their main substances of misuse. At 18 months $38 \%$ of patients had failed to remain engaged with the service.

\section{CLINICAL IMPLICATIONS}

This specialist type of service may be more useful than other services in engaging patients with comorbidity. Systematic research is required in the UK to explore the effectiveness of this type of new service. More innovative resources need to be identified to specifically deal with patients with severe mental illness and comorbid substance use.
There is an accumulation of evidence suggesting that mental illness with comorbid drug use requires specific targeting (Teague et al, 1995) and, further, should be a determinant of health authority spending on mental health (Appleby et al, 1999: p.11, Recommendation 7). Crome (1999) suggests that the relationship is complex as there are 10 ways in which mental illness and substance misuse interact. Moreover, substance misuse in dual diagnosis patients is associated with non-compliance with psychotropic medication. It may also lead to prescribed medication being inadequate to maintain remission. Both may lead to an increase in service use (Menezes et al, 1996). There is often a gap in the provision of services to these individuals when the mental health and addiction services try to treat these patients independently (Appleby, 2000). Despite this, there has been only sporadic funding of mental health initiatives for this challenging group.

The mental illness and drug and alcohol services (MIDAS) in East Hertsmere represents one such initiative involving the West Hertfordshire Health Authority. The remit of this service is to target patients with a severe mental illness who show evidence of drug and alcohol use that significantly interferes with the health of these individuals. An assertive outreach posture is frequently required for this group because of their lack of reliable contact with conventional mental health services. It may also be needed because of paucity of social networks, or poor compliance (Drake \& Wallach, 1989).

\section{The current service}

MIDAS provides a wide-ranging and specialist service for the 16-65-year age group. The team is based in a mixed urban and rural setting in Hertfordshire, covering a population currently estimated at 68000 . The base for this service is a semi-detached house in the town centre, 3 miles from the main hospital. Assessments are completed outside of a ward environment, in a relaxed and patient-friendly atmosphere. Staffing consists of three community psychiatric nurses, two drug and alcohol workers, two care support workers and one administrative worker. There are two sessions of staff grade psychiatric time and consultant cover during the week. Staff provide cover from 9 a.m. to 5 p.m. 5 days a week. After-hours cover is provided by a 24 -hour crisis intervention team

The service provided by MIDAS has four components: (a) a comprehensive initial assessment within 1 week of
accepting a referral 
(b) monitoring of mental illness and drug and alcohol use via an assertive outreach approach

original papers

(c) individualised case management via a multi-disciplinary approach

(d) integration of substance misuse and psychiatric illness management.

The therapeutic options offered include individual supportive therapy, education and advice on financial and housing issues. There are also family meetings. The team engage patients in relaxation techniques including acupuncture and recreational support in the form of exercise at the gym, swimming, line-dancing, football, gardening, using a sauna and playing in a band. This is in addition to the team providing conventional medical and psychiatric support to all patients. Depot injections and out-patient appointments also occur on site.

\section{Referrals}

Referrals to MIDAS are accepted if the patient has evidence of an acute or chronic mental disorder as well as a comorbid drug or alcohol problem. Referrals are accepted from within the community mental health team. External referrals, for example from general practitioners (GPs), are first assessed by the general psychiatric team. Patients with primary drug and/or alcohol misuse, but no other psychiatric, problems and organic brain syndromes (e.g. dementia, delirium or amnesic syndrome) are excluded from the service.

\section{The study}

The case files of the first 80 patients accepted by MIDAS between April 1998 and January 1999 were studied.
Diagnoses were made using ICD-10 (World Health Organization, 1992). A retrospective case note analysis was undertaken by a consultant psychiatrist not directly linked to the MIDAS service (R.B.). Information collected included personal and associated demographic details and psychiatric, substance and social histories.

\section{Findings}

The acceptance rate to the service was $80 / 84$ (98\%). Of those accepted, 49 (61\%) were male and the average age was 34 (range 20 -59). Seventeen (21\%) were married or cohabiting, 13 (16\%) were divorced or separated and 50 $(63 \%)$ were single. Eleven (14\%) were working and 18 (22\%) were homeowners. Fifty (63\%) were living alone. Thirty-seven $(46 \%)$ were registered at only two of the nine general practices within the area.

Table 1 shows the characteristics of the patients with reference to their diagnosis. The patients had spent on average 5.6 years (Range 1 month-30 years) in contact with the psychiatric services before referral to MIDAS. Thirty-two (40\%) were born locally. Fourteen (18\%) had worked in the year prior to assessment. Twenty-two $(27 \%)$ had no contact with their family in the preceding 3 months. None had been in care as a child. Eighty (100\%) were White Caucasian, of whom 80 (100\%) were British born.

Thirty-one (39\%) had a prior criminal conviction other than a driving offence and $10(13 \%)$ had previously been imprisoned (Table 2). Fifty-two (66\%) had a history of in-patient treatment. One $(1.25 \%)$ had spent more than 1 continuous year as an in-patient. Table 3 gives a breakdown of reasons why patients failed to remain

Table 1. Comparison of variables between patients with different diagnoses

\begin{tabular}{|c|c|c|c|c|c|c|}
\hline Diagnosis & $\begin{array}{c}\text { Number of patients } \\
\text { referred (\%) }\end{array}$ & $\begin{array}{l}\text { Male } \\
(\%)\end{array}$ & $\begin{array}{c}\text { Female } \\
(\%)\end{array}$ & $\begin{array}{c}\text { Number still engaged } \\
\text { at } 1 \text { year }(\%)\end{array}$ & $\begin{array}{l}\text { Main drug } \\
\text { of choice }\end{array}$ & $\begin{array}{l}\text { 2nd drug } \\
\text { of choice }\end{array}$ \\
\hline Bipolar disorder & $4 \quad(5)$ & 2 & 2 & $4(100)$ & Alcohol & Cannabis \\
\hline Unipolar disorder & $8(10)$ & 6 & 2 & $3(38)$ & Alcohol & Cannabis \\
\hline Drug-induced psychosis & $10(12.5)$ & 8 & 2 & $5 \quad(50)$ & Cannabis & Alcohol \\
\hline No enduring psychiatric disorder & $19(24)$ & 13 & 6 & $8(42)$ & Alcohol & Cannabis \\
\hline Other & $5 \quad(6)$ & 2 & 3 & $1 \quad(20)$ & Cannabis & Alcohol \\
\hline Total & $80(100)$ & 49 & 31 & $41 \quad(51)$ & & \\
\hline
\end{tabular}

Table 2. Prior admission rates and forensic profile by diagnosis

\begin{tabular}{|lccr} 
Diagnosis & $\begin{array}{c}\text { Average previous admissions } \\
\text { per patient }\end{array}$ & $\begin{array}{c}\text { Number of patients with } \\
\text { previous convictions (\%) }\end{array}$ & $\begin{array}{c}\text { Number of patients previously } \\
\text { imprisoned (\%) }\end{array}$ \\
\hline Schizophrenia & 2.8 & $11(61)$ & $4(22)$ \\
Bipolar disorder & 4.3 & $2(50)$ & $1(25)$ \\
Unipolar disorder & 0.9 & $1(12.5)$ & 0 \\
Drug induced psychosis & 1.4 & $5(50)$ & $2(20)$ \\
Personality disorder & 3.8 & $7(44)$ & $3(6)$ \\
No psychiatric illness & 1.9 & $10(53)$ & $1(16)$ \\
Other & 2.4 & $2(40)$ & $12(15)$
\end{tabular}


Table 3. Reasons for loss of contact with patient at 18 months

Reason for loss of contact

Non-engagement with treatment

Moved away from area

Alternative plan organised by team

No longer ill

Total

Table 4. Mental illness and drug and alcohol services (MIDAS)

most frequently used by patients

\begin{tabular}{|lc} 
Services provided by MIDAS & $\begin{array}{c}\text { Number of patients } \\
\text { using each service (\%) }\end{array}$ \\
\hline Individual counselling & $67(84)$ \\
Relaxation & $52(65)$ \\
Sports and recreation & $35(44)$ \\
Benefits & $26(32)$ \\
Escort & $23(29)$ \\
Depot & $19(24)$ \\
\hline
\end{tabular}

engaged and Table 4 shows the number of patients using some of the other services offered by MIDAS.

\section{Comment}

Little is known about which patients benefit most from this type of service. The basic demographic data do not help to predict responders to the service. One-fifth of patients had a personality disorder and nearly a quarter had schizophrenia. It is difficult to ascertain whether these subgroups within the study are prone to a higher burden of substance misuse without first knowing the total population that they are recruited from, but the question remains of whether substance misuse favours particular psychiatric illnesses.

\section{Patterns of engagement}

Patients with personality disorder were longer-term users compared to other groups. It might be expected that patients with schizophrenia would be short-term users of the service considering reported poor compliance with treatment (Bebbington, 1995). This is reflected in our study as these patients showed a $61 \%$ drop-out rate in the first year. Although $55 \%$ of patients had disengaged from the service at 18 months, only 38\% had left owing to non-engagement with treatment. This is similar to previous assertive community treatment programmes (Bond et al, 1991). In that study, controls receiving normal treatments had a drop-out rate of $60 \%$.

\section{Substances used}

Patients with schizophrenia in this population used alcohol and cannabis as their main drugs of misuse. This reflects the general population, where psychostimulants are used less frequently. Other studies have shown similar results (Drake \& Noordsy, 1994; Lehman et al, 1994). This is not in keeping with the reviews by Schneider and Siris (1987) and Wright and Klee (1999, 2001), where the population with schizophrenia used psychostimulants more frequently. Of the 19 patients with schizophrenia referred, only four $(22.2 \%)$ reported psychostimulant use on a regular basis as well as other substances. Our finding is in keeping with Cuffel et al (1993), that there are two groups of substance misusers. The first have high levels of alcohol and cannabis use with very limited use of other substances and the other use many substances including alcohol and cannabis.

\section{Access to primary care}

Forty-six per cent of patients were registered at only two of the nine general practices in the area. This is much higher than the expected figure of $22(27 \%)$ based on the practice size and assuming an even distribution of patients across the practices. The authors have no knowledge of this phenomenon occurring previously. It may be due to small high-density pockets of dual diagnosis patients in their locality, possibly as a result of housing. It may also be that patients with severe mental illness and substance misuse have difficulty registering with local GPs, although this remains to be tested. This would be a cause for concern if it was a nationwide phenomenon.

\section{Prior forensic history}

The percentage of patients with previous convictions in this study is high (46\%). This figure is even higher for patients with schizophrenia and comorbid drug use (61\%).

The pattern is consistent with previous reports (Scott et al, 1998). Possible explanations include intoxication leading to offending activity, a higher incidence of dissocial personality traits or a higher rate of non-compliance in the dual diagnosis group. In another study, Soyka (1993) found that patients with schizophrenia and substance misuse had a conviction rate of $40.1 \%$ compared to $13.7 \%$ for schizophrenia alone. The higher rate of forensic activity in the MIDAS population is alarming, but may be explained by the relatively small numbers in the study.

\section{Limitations of the service}

Initial results may prove to be unrepresentative when compared to longer periods of study and different phases of MIDAS, as this initial survey included $25 \%$ of patients without dual diagnosis. Limitations of the service are reflected in the high drop-out rates of those patients with schizophrenia or unipolar disorder. Future randomisation to this or similar services would be appropriate to determine the clinical effectiveness and costeffectiveness of this type of service delivery compared to generic drug and alcohol or psychiatric services. Other problems are that the results of the study are not original papers 
easily generalisable to inner-city areas, especially as the population was not multiracial. Ethnic minorities in East Hertsmere represent less than $0.1 \%$ of the population and original papers

were not under-represented in the referral group.

\section{Potential advantages of the service}

The service described above can be seen as pioneering and providing a wide range of treatment options simultaneously for both severe mental illness and substance misuse. Some aspects are new and some are combinations of older methods of service delivery. At present there is no clinical trial evidence for the effectiveness of any intervention for patients with severe mental illness and comorbid substance misuse (Weaver et al, 1999).

We suggest the beneficial aspects of the service that have been established so far may be a result of the development of a broad-ranging mainstream service with a model of treatment informed from a multi-disciplinary perspective. This is in line with recent recommendations (Appleby et al, 1999: p.12, Recommendation 14). The service is different in that there is less chance of becoming limited in perspective, which might occur in a team dealing solely with substance misuse or solely with psychiatric illness. Also, an established benefit is good communication within the team about both the mental health and substance misuse aspects of each patient. This is distinct from services that communicate specifically about only one aspect of the patients' comorbidity and are also unable to accommodate new needs rapidly. An example is the ability to access in-patient admissions for early detoxification before secondary deterioration of mental health or social circumstances. The other beneficial aspects of the service are as follows:

(a) ease of access to the team both in terms of its position in the heart of the town centre and the high acceptance rate

(b) the active assertive response to improve patient concordances

(c) the rapid availability of individual counselling, support and intervention on a daily basis if necessary

(d) domiciliary assessments and treatment in the community, which seem to be more acceptable and enjoyable to patients than attending hospital outpatients or being assessed as an in-patient

(e) active collaboration with other hospital and community professionals to provide an individualised care package

(f) educational programmes for patients

(g) a high level of input for issues surrounding financial and housing difficulties, decreasing the burden on other agencies

(h) the composition and organisation of the team allows mutual cooperation so that patients can be seen rapidly and regularly by one or several members of the team

(i) a rapid response to referrals

(j) the problem of differential funding for psychiatric and substance misuse is avoided. Emphasis is placed upon any and all difficulties to enable integrated care (k) continued involvement in a patient's care if readmitted to hospital, which may have facilitated shorter stays in hospital.

\section{Acknowledgement}

We wish to thank the staff at the Hertsmere MIDAS team for their help with providing data for this paper.

\section{Declaration of interest}

None.

\section{References}

APPLEBY, L. (2000) Safer services: conclusions from the National Confidential Inquiry. Advances in Psychiatric Treatment, 1, 5-15.

-, SHAW, J., AMOS, T., et al (1999) Safer Services. Report of the Nationa Confidential Inquiry into Suicide and Homicide by People with Mental Illness. London: Department of Health.

BEBBINGTON, P. (1995) The content and context of compliance. International Clinical Psychopharmacology, 9(suppl. 5), 41-50

BOND, G. R., MCDONEL, B. C., MILLER, L. D., et al (1991) Assertive community treatment and reference groups: an evaluation of their effectiveness for young adults with serious mental illness and substance abuse problems. Psycho

Social Rehabilitation Journal, 15(2) $31-43$

CROME, J. B. (1999) Substance misuse and psychiatric comorbidity: towards improved service provision. Drugs: Education, Prevention and Policy, 6 , 151-174.

CUFFEL, B. J., HEITHOFF, K. A. \& LAWSON,W. (1993) Correlates of patterns of substance abuse among patients with schizophrenia. Hospital and Community Psychiatry, 44, 247-251.

DRAKE, R. \& NOORDSY, D. (1994) Diagnosis of alcohol use disorders in schizophrenia. Schizophrenia Bulletin, $16,57-67$.

DRAKE, R. E. \& WALLACH, M. A. (1989) Substance abuse among the chronic mentally ill. Hospital and Community Psychiatry, 40, 1041-1046.

LEHMAN, A., MYERS, C., DICKSON, L., et al (1994) Defining sub-groups of dual diagnosis patients for service planning. Hospital and Community Psychiatry, $\mathbf{4 5}$ 556-561.

MENEZES, P. R., JOHNSON, S. THORNICROFT, G., et al (1996) Drug and alcohol problems among individuals with severe mental illness in South London. British Journal of Psychiatry, $168,612-619$.

SCHNEIDER, F. R. \& SIRIS, S. G. (1987) A review of psychoactive substance use and abuse in schizophrenia: pattern of drug choice. Journal of Nervous and Mental Disease, 175, 641-652

SCOTT, H., JOHNSON, S., MENEZES, P., et al (1998) Substance misuse and risk of aggression and offending among the severely mentally ill. British Journal of Psychiatry, 172, 345-350.

SOYKA, M. (1993) Substance abuse and dependency as a risk factor for delinquency and violent behaviour in schizophrenic patients - how strong is the evidence? Journal of Clinical Forensic Medicine, 1, 3-7.

TEAGUE, G., DRAKE, R. \& ACKERSON,T. (1995) Evaluating use of continuous treatment teams for persons with mental illness and substance abuse. Psychiatric Services, 46, 689-695.

WEAVER, T., RENTON, A., STIMSON G., et al (1999) Severe mental illness and substance misuse. BMJ, 318 137-138.

WORLD HEALTH ORGANIZATION (1992) The ICD-10 Classification of Menta and Behavioural Disorders. Geneva: WHO.

WRIGHT, S. \& KLEE, H. (1999) A profile of amphetamine users who present to treatment services and do not return. Drugs: Education, Prevention and Policy, 6, 227-241.

- \& - (2001) Violent crime,

aggression and amphetamine: what are the implications for drug treatment services. Drugs: Education, Prevention and Policy, 8, 73-90.

*Richard Bayney Honorary Lecturer/Specialist Registrar, West London Mental Health Care NHS Trust, Uxbridge Road, Southall, Middlesex UB1 3EU, Paul St John-Smith Consultant Psychiatrist in MIDAS and Adult Mental Health, Cranbourne Centre, Potters Bar, Anand Conhye Manager/Specialist Practitioner at MIDAS, Borehamwood 